\title{
Intake of paired sucrose solutions in long and short tests '
}

DONALD H. OWINGS AND ROBERT B. LOCKARD UNIVERSITY OF WASHINGTON

Albino rats were presented with one of five pairs of sucrose solution $(0-2,2-4,4-8,8-16,16-32 \%)$ for 11 consecutive daily tests of $1 \mathrm{~h}$ or $23 \mathrm{~h}$ duration. Frequency of preference for the lower concentrations of the pairs was an increasing function of concentration and test duration.

Several studies have demonstrated that when sucrose solutions are paired in an intake test, intake is, generally, a monotonically increasing function of concentration (Young and Greene, 1953; Campbell, 1958). Within the data from these studies, however, exists evidence for the hypothesis that the monotonically increasing intake function occurs under a more restricted set of conditions than previously believed. Young and Greene found that some unexplained reversals in relative intake occurred on the last of a series of six daily tests. Campbell paired a wide range of concentrations of sucrose solution and found that although intake was usually greater for the higher concentration of a pair, inflections in the intake function occurred at the highest concentrations. It is possible, then, that the probability of occurrence of the monotonically increasing sucrose intake function is a decreasing function of the number of previous tests and the concentration of solutions. The purpose of this study was to test this hypothesis and, also, to test the effects of test duration.

Method

The Ss were 40 male Holtzmann albino rats, 120 days old and weighing from 350-500 g. The Ss were maintained in stainless steel cages ( $16 \times 10 \times 7$ in.) with wire mesh floors and fronts. Each cage was partitioned longitudinally such that two rats could be maintained and tested in each cage. Fluid was presented in glass drinking bottles with stainless steel drinking tubes extending $1 / 4 \mathrm{in}$. into the cage and $11 / 2 \mathrm{in}$. above the floor. Cage illumination was about 1.2 foot-candles. Ss were maintained on a 12L:12D light-dark cycle.

Concentrations of sucrose used were 0 (tap water), $2,4,8,16$, and $32 \%$ by weight of solute and solvent, e.g., $2 \%$ is $2 \mathrm{~g}$ of sugar in $98 \mathrm{~g}$ of water (Pfaffman et al., 1954). All solutions were mixed with tap water and were used only at room temperature. A stock solution was kept (for a maximum of 3 days) and refrigerated between tests; all other solutions were made by dilution of this solution.

Eight rats were randomly assigned to each of five different pairs of solutions-0-2, 2-4, 4-8, 8-16,16-32. One half of the rats in each group were given a $1 \mathrm{~h}$ test daily and one jalf were given a $23 \mathrm{~h}$ test daily. Water was available to the rats only during non-test periods.

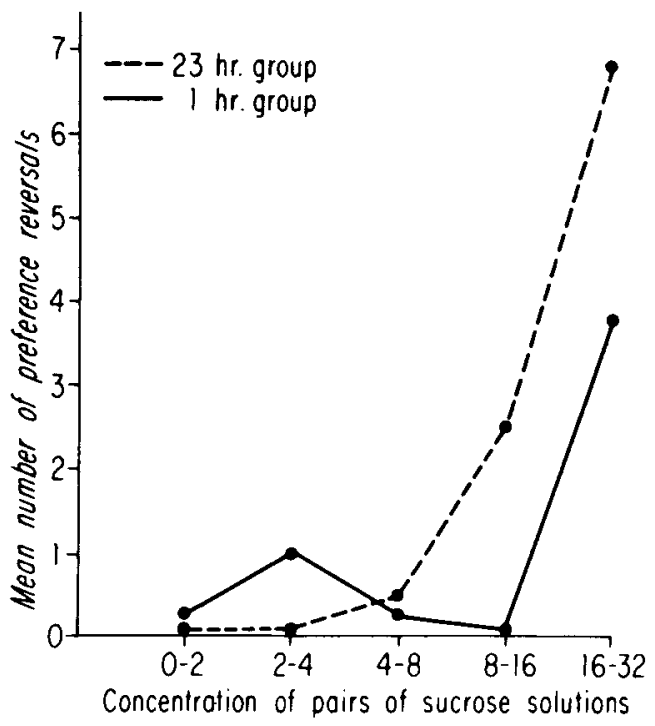

Fig. 1. Mean number of days on which preference reversals occurred as a function of concentration of pairs of sucrose solution and test duration.

The positions of test solutions were alternated each day. Measures were taken of amount of each sucrose solution drunk during test periods.

All Ss were tested each day for 11 days. Food was available ad lib in feeding tubes extending through the front of each cage.

Results

The basic data (intake of two solutions for each $\mathrm{S}$ for each day) were converted into proportions (intake of higher concentration/intake of higher + lower concentration) for each $\mathrm{S}$ for each day. A duration of exposure by concentrations of pairs by days analysis of variance was performed upon these proportions. The mean frequency with which these daily proportions assumed a value of 0.50 or lower (hereafter called a "preference reversal") was computed for each of the 10 groups, and is plotted as a function of duration of exposure and concentrations of pairs of solutions in Fig. 1. It is clear from the curves that concentration was a highly significant variable $(F=30.24, \mathrm{df}=4 / 30, \mathrm{p}<.01)$. Those rats having access to pairs of solutions involving concentrations of 4 to $8 \%$ or lower consistently drank more of the higher concentration of their pair. There were a few exceptions, but these occurred only during early days of testing when failures either to drink or to sample both solutions occurred. Those Ss exposed to higher concentrations, however, exhibited preference 
reversals, the frequency of which increased with concentration. The concentration variable interacted significantly with test duration $(F=9.02, d f=4 / 30, p<.01)$, resulting primarily from the lower frequency of preference reversals in the $1 \mathrm{~h}$ groups relative to the $23 \mathrm{~h}$ groups.

The reversals in relative preference occurred approximately on alternating days for individual Ss. That these fluctuations did not lead to a significant "days" effect $(F<1.0)$ in the analysis is attributable to the facts that the fluctuations were not "in phase," and that not all Ss fluctuated. The "days" effects, however, interacted significantly with concentration $(F=1.74, \mathrm{df}=$ $40 / 300, p<.01$ ), resulting from the larger and more frequent fluctuations in relative intake within the higher concentration groups, than within those with lower concentrations.

\section{Discussion}

The monotonically increasing intake function is, then, a transient phenomenon: the rapidity or frequency with which it disappears depends upon several factors. The fact that the 16-32 groups exhibited the most frequent preference reversals suggests that one of these factors is concentration of test solutions. Substantiating this possibility is the fact that Cambell's (1958) rats exhibited higher intake of the lower concentration of a pair only at the highest concentrations. It is possible that Yound and Greene found only infrequent preference reversals because they used only a single pair of concentrations ( 9 and $36 \%$ ), and because these concentrations were widely separated. Pilot data in this lab indicate that when 8 and $32 \%$ are paired in a $23 \mathrm{~h}$ test, inflections in the intake function are very rare.

The tendency for $\mathrm{Ss}$ in the $23 \mathrm{~h}$ test group to exhibit a higher frequency of preference reversals than Ss in the $1 \mathrm{~h}$ group suggests that either test duration or intertest interval is another important variable. This finding suggests that another reason that Young and Greene found only very rare inflections in the intake function is that they used only $1 \mathrm{~h}$ daily tests.

The cyclic character of the reversals suggests that some state within the organism builds up as a result of prolonged ingestion of concentrated sucrose solutions. This state, however, is alleviated only if some alternative concentration is available which is lower, but not too much lower, than the concentrated solution. Carpenter (1958), for instance, reported that very little water was ingested when sucrose solutions were paired with water. Further evidence comes from the previously cited rarity of preference reversals when widely separated solutions were paired. The willingness of the rat to alleviate this state, then, appears to have a "flavor" contingency associated with it. Furthermore, the state appears to have some factors in common with the postingestive state which determines the shape of the single bottle sucrose intake function. The single bottle intake function peaks at 4 to $8 \%$ (Owings, Haerer, \& Lockard, 1967; Young, 1949); similarly preference reversals appeared to occur at pairs of solutions involving concentrations of $8 \%$, or higher.

In conclusion, the test duration-and relative and absolute concentration-variables appear to be important in determining the probability of obtaining a monotonically increasing function relating sucrose intake, of domesticated rats, to concentration. Effects of number of tests interact with concentration, but do not appear to be important as main effects. Determination of the characteristics of the internal state which mediates preference reversals will require further study.

\section{References}

CAMPBELL, B. A. Absolute and relative sucrose preference thresholds for hungry and satiated rats. J. comp. physiol. Psychol, 1958, 51, 795-800.

CARPENTER, J. A. A comparison of stimulus-presentation procedures in taste-preference experiments. J. comp. physiol. Psychol., 1958,51, 561-564.

OWINGS, D. H., HAERER, H. A., \& LOCKARD, R. B. Sucrose intake functions of rat and cockroach for single and six solution presentations. Psychon. Sci, 1967, 7, 125-126.

PFAFFMAN, C., YOUNG, P. T., DETHIER, V. G., RICHTER, C. P., \& STELLER, E. The preparation of solutions for research in chemoreception and food acceptance. J. comp. physiol Psychol., 1954, 47, 93-96.

YOUNG, P. T. Palatability versus appetite as determinants of the critical concentrations of sucrose and sodium chloride. Comp. psychol. Monogr., 1949, 19, \#5.

YOUNG, P. T., \& GREENE, J. T. Quantity of food ingested as a measure of relative acceptability. J. comp. physiol. Psychol., 1953, 46, 288-294.

Notes

1. This research was supported by Grant GB-3141 from the National Science Foundation. 